\title{
Guidelines
}

European

Thyroid Journal
Eur Thyroid J 2017;6:225-237

DOI: $10.1159 / 000478927$
Received: May 4, 2017

Accepted: June 17, 2017

Published online: August 8, 2017

\section{European Thyroid Association Guidelines for Ultrasound Malignancy Risk Stratification of Thyroid Nodules in Adults: The EU-TIRADS}

\author{
Gilles Russ $^{\mathrm{a}}$ Steen J. Bonnema ${ }^{\mathrm{b}}$ Murat Faik Erdogan ${ }^{\mathrm{c}}$ Cosimo Durante ${ }^{\mathrm{d}}$ \\ Rose $\mathrm{Ngu}^{\mathrm{e}}$ Laurence Leenhardt ${ }^{\mathrm{a}}$

\begin{abstract}
${ }^{a}$ Thyroid and Endocrine Tumors, Institute of Endocrinology, Pitié Salpêtrière Hospital, Pierre and Marie Curie University, Paris, France; ${ }^{b}$ Department of Endocrinology, Odense University Hospital, Odense, Denmark; 'Department of Endocrinology and Metabolism, University of Ankara School of Medicine, İbni Sina Hastanesi, Ankara, Turkey; ${ }^{d}$ Department of Internal Medicine and Medical Specialties, Sapienza University of Rome, Rome,

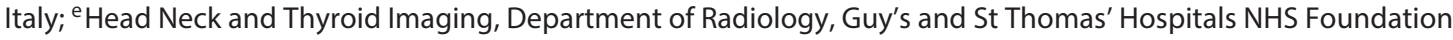
Trust, London, UK
\end{abstract}

\section{Keywords}

Ultrasound · Thyroid nodule $\cdot$ Risk of malignancy ·

Fine needle aspiration · TIRADS · Guidelines

\begin{abstract}
Thyroid ultrasound (US) is a key examination for the management of thyroid nodules. Thyroid US is easily accessible, noninvasive, and cost-effective, and is a mandatory step in the workup of thyroid nodules. The main disadvantage of the method is that it is operator dependent. Thyroid US assessment of the risk of malignancy is crucial in patients with nodules, in order to select those who should have a fine needle aspiration (FNA) biopsy performed. Due to the pivotal role of thyroid US in the management of patients with nodules, the European Thyroid Association convened a panel of international experts to set up European guidelines on US risk stratification of thyroid nodules. Based on a review of the literature and on the American Association of Clinical Endocrinologists, American Thyroid Association, and Korean guidelines, the panel created the novel European Thyroid Imaging and Reporting Data System, called EU-TIRADS. This comprises a thyroid US lexicon; a standardized report; definitions of benign and low-, intermediate-, and high-risk nod-
\end{abstract}

ules, with the estimated risks of malignancy in each category; and indications for FNA. Illustrated by numerous US images, the EU-TIRADS aims to serve physicians in their clinical practice, to enhance the interobserver reproducibility of descriptions, and to simplify communication of the results.

(c) 2017 European Thyroid Association Published by S. Karger AG, Basel

\section{Background and Objectives}

\section{Purpose of Thyroid Nodule Risk Stratification}

The majority of thyroid nodules are incidental findings of asymptomatic, benign lesions discovered by imaging examinations for reasons unrelated to the thyroid [1]. The goal of an initial sonographic assessment of thyroid nodules is to distinguish benign nodules that can be managed conservatively from those with suspicious or malignant features requiring further management. Fine needle aspiration (FNA) plays a central role in this process, but its performance needs to be selective, since systematic FNA of all nodules, regardless of the size or appearance, is superfluous and may even lead to unnecessary diagnostic thyroid surgery $[2,3]$. Crucially, besides clinical pa-

\section{KARGER}

E-Mail karger@karger.com

www.karger.com/etj (c) 2017 European Thyroid Association

Published by S. Karger AG, Basel
Laurence Leenhardt, MD, PhD

Thyroid and Endocrine Tumors Institute of Endocrinology, Pitié Salpêtrière Hospital Pierre and Marie Curie University, 83 Bd de l'Hôpital

FR-75651 Paris Cedex 13 (France)

E-Mail laurence.leenhardt@aphp.fr 
rameters, indications for FNA should be based on ultrasonographic malignancy risk stratification alongside clinical risk factors.

\section{Accuracy of Thyroid Ultrasound Features}

Certain features of thyroid nodules on ultrasound (US) are consistently predictive of malignancy and are used as criteria for FNA [3-6]. These criteria have various sensitivity and specificity, but unfortunately none of them alone is sufficient to discard or detect malignancy efficiently [7-10]. Furthermore, there is substantial interobserver variation in the assessment and reporting of some of the US patterns [11].

Looking at recent meta-analyses of US accuracy in the prediction of thyroid cancer [8-10], Brito et al. [8] included 31 studies and a total of 18,288 nodules, of which $20 \%$ were thyroid cancer. The features with the highest diagnostic odds ratio (DOR) for predicting malignancy were a "taller-than-wide" shape (11.1; 95\% CI: 6.6-18.9) and internal calcifications (6.8; 95\% CI: 4.5-10.2), while a spongiform (12; 95\% CI: 0.6-234.3) and a cystic appearance $(6.8$; 95\% CI: 2.3-20.3) most reliably predicted benignity [8]. Nodule size was a poor predictor. Experienced physicians performed better in the interpretation of internal calcifications than did less experienced colleagues (DOR of 14.5 vs. 5.4) [8]. Two more meta-analyses $[9,10]$ included 52 and 41 observational studies and a total of 12,786 and 29,678 nodules, respectively. In unselected nodules, all features were significantly associated with malignancy, showing DORs in the ranges of 1.8-35.7 [9] and 1.2-10.2 [10]. Remonti et al. [9] found the highest specificities for absence of elasticity, microcalcifications, irregular margins, and a "taller-than-wide" shape (86.2, 87.8, 83.1, and 96.6\%, respectively). Campanella et al. [10] reported similar findings, as the highest risk of malignancy was associated with a "taller-than-wide" shape (DOR of 10.2; 95\% CI: 6.7-15.3), an absent halo sign (7.1; 95\% CI: 3.7-13.7), microcalcifications (6.8; 95\% CI: 4.7-9.7), and irregular margins (6.1; 95\% CI: 3.1-12.0).

\section{Existing Guidelines and US Scoring Systems}

As no single US feature can reliably predict malignancy, the approach should be to combine several features ("classic pattern" recognition) to enhance the diagnostic value of US [12]. This has prompted the development of standardized systems for reporting US features, in an attempt to delineate sets of characteristics associated with specific risk levels for malignancy [13]. Based on the "classic pattern" concept, a tool for US classification of thyroid nodules was developed by Horvath et al. [14] in
2009, known as the Thyroid Imaging Reporting and Data System (TIRADS). This is a system similar to the one used for breast imaging. It consists of a 6-point scale for risk stratification with increasing risks of malignancy. Endorsed by the French Society of Endocrinology in 2011, it was subsequently modified into an easier-to-use version, which was validated in a large prospective study [15].

Recently, similar recommendations have been issued by the Korean Society of Thyroid Radiology, the American Thyroid Association, the American Association of Clinical Endocrinologists, the American College of Endocrinology, and the Italian Associazione Medici Endocrinologi [16-18]. None of these recommendations have been validated in large-scale prospective studies, and all systems are mainly based on papillary thyroid cancers (PTCs). The scoring systems have been evaluated by a meta-analysis of 10,437 nodules [19], which found that on the average TIRADS had a good sensitivity and specificity of 79 and $71 \%$, respectively. The diagnostic values of the world's most widely used TIRADS [15-20] are shown in online supplementary Table 1 (see www. karger.com/doi/10.1159/000478927 for all online suppl. material), and the comparison made between the different systems is displayed in online supplementary Table 2.

The justification for developing a new US classification system was (1) to integrate into a single system a lexicon and illustrated atlas, a standardized report and diagram (not included in the American Thyroid Association and American Association of Clinical Endocrinologists guidelines), and a scoring method and (2) to seek for a simpler scoring system than the others, taking into account as few criteria as possible to evaluate the malignancy risk of nodules and to detail the US semiology used.

\section{Aims and Objectives}

Considering the extensive use of thyroid US in the management of thyroid nodules, the ETA Executive Committee set up a task force for the following reasons:

- To create guidelines and a standardized risk stratification system, called EU-TIRADS, to assess the risk features of thyroid malignancy

- To establish a standard US description lexicon

- To provide selection criteria for FNA

- To provide a structured US reporting template

- To provide a practical image guide for clinical usage

For "Working methods and grading of recommendations," see the online supplementary material. 


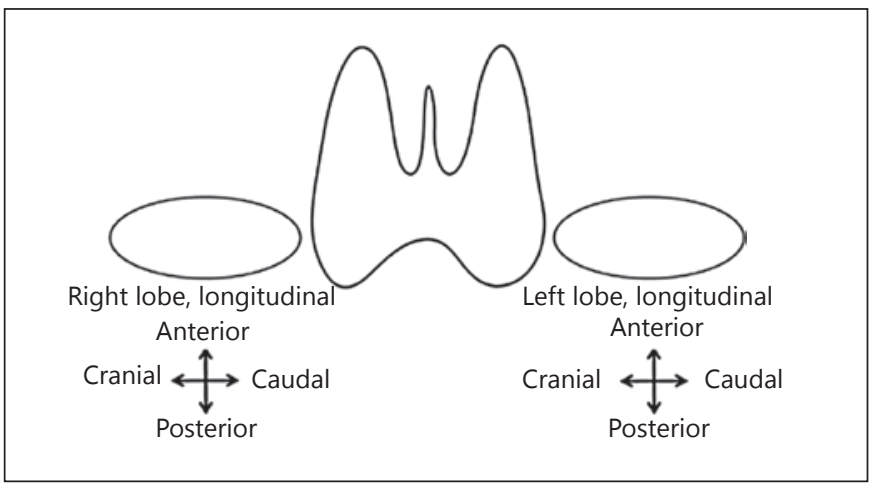

Fig. 1. Example of a drawing to locate and number thyroid nodules.

\section{Reporting Thyroid US Findings [21-23]}

A structured and standardized report aimed at communicating thyroid and neck US findings in a clear and consistent fashion is an important part of the EUTIRADS (Table 1), as well as a terminology lexicon (Appendix on US Terminology of Thyroid Nodules) [21-23]. An example of the drawing is given in Figure 1 [24].

\section{Recommendation}

R1: US examination for thyroid nodules should include a malignancy risk assessment based on risk stratification and scoring. Use of the standardized lexicon, report, and drawing is advised.

Quality of evidence (QOE) $=++$; Strength of recommendation $(\mathrm{SOR})=$ grade 1

\section{EU-TIRADS: US Classification System for Risk of Thyroid Carcinoma}

This section provides thyroid US definitions of benign and low-, intermediate-, and high-risk nodules, as well as recommendations for FNA $[9,10,14-18]$. The EUTIRADS 1 category refers to a US examination where no thyroid nodule is found. Indications for FNA should also be based on clinical risk factors and be in agreement with the patient. Moreover, FNA should not be performed on a nodule if thyroid scintigraphy (if performed) shows this to be warm/hot. Accordingly, performance of thyroid scintigraphy is justified in case the serum thyroid-stimulating hormone level is low to normal, especially in iodine-deficient countries, in order to avoid useless FNAs of hot nodules, which are almost always benign.

Guidelines for US Malignancy Risk

Stratification of Thyroid Nodules in Adults
Table 1. Standardized reporting

\begin{tabular}{ll}
\hline Technique & $\begin{array}{l}\text { US equipment, type of probe } \\
\text { Patient with compromising factors }\end{array}$ \\
\hline History & $\begin{array}{l}\text { Family history of thyroid cancer } \\
\text { History of neck irradiation during childhood, or } \\
\text { known operative history with regard to the neck } \\
\text { or thyroid } \\
\text { Former FNA results }\end{array}$ \\
\hline Results & Thyroid volume \\
& Echogenicity and vascularity of the gland \\
& Nodules (above 5 mm unless highly suspect) \\
& Location (side, superior, medial, inferior) \\
& Size (3 diameters +/- volume) \\
& Shape, margins, echogenicity, composition, \\
& echogenic foci \\
& EU-TIRADS score \\
& Numbered and mapped out on the thyroid \\
& map \\
& Change of size \\
& Retrosternal extension \\
& Trachea deviation \\
Study of lymph nodes (levels II, III, IV, V, VI) \\
and of the thyroglossal duct
\end{tabular}

US, ultrasound; FNA, fine needle aspiration; EU-TIRADS, European Thyroid Imaging Reporting and Data System.

Benign Category (EU-TIRADS 2)

Risk of malignancy: close to $0 \%[5,25]$.

\section{Definition}

This category includes two patterns: pure/anechoic cysts (Fig. 2) and entirely spongiform nodules (Fig. 3).

\section{Background and Comments}

In this category, thyroid US should suffice to assert benignity without the need for FNA.

Purely Cystic Nodules. Absence of wall thickening or a solid component; disregard their size. This category includes cysts which are split into separate compartments by a few traversing septa. The presence of echogenic material inside the cyst is frequently encountered and can correspond either to a fibrin clot or a true solid component, which may be differentiated by the application of Doppler US. If doubt persists regarding the existence of a 

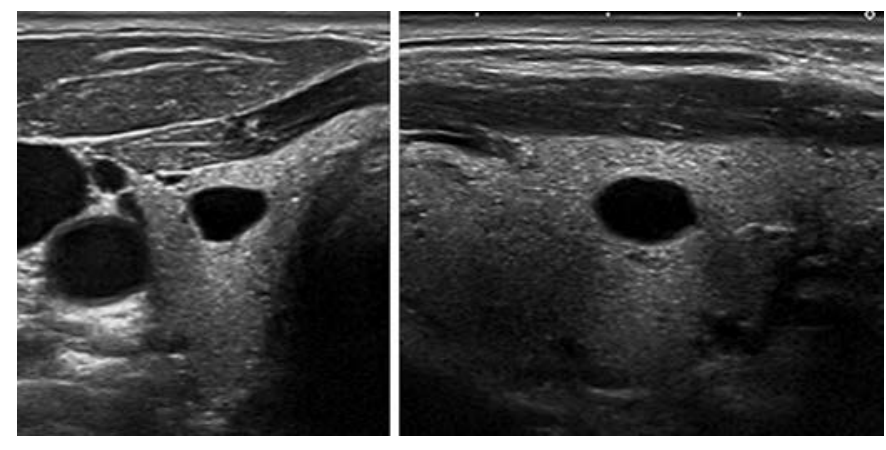

Fig. 2. EU-TIRADS 2: pure/anechoic cyst. Transverse (left) and longitudinal (right) planes.

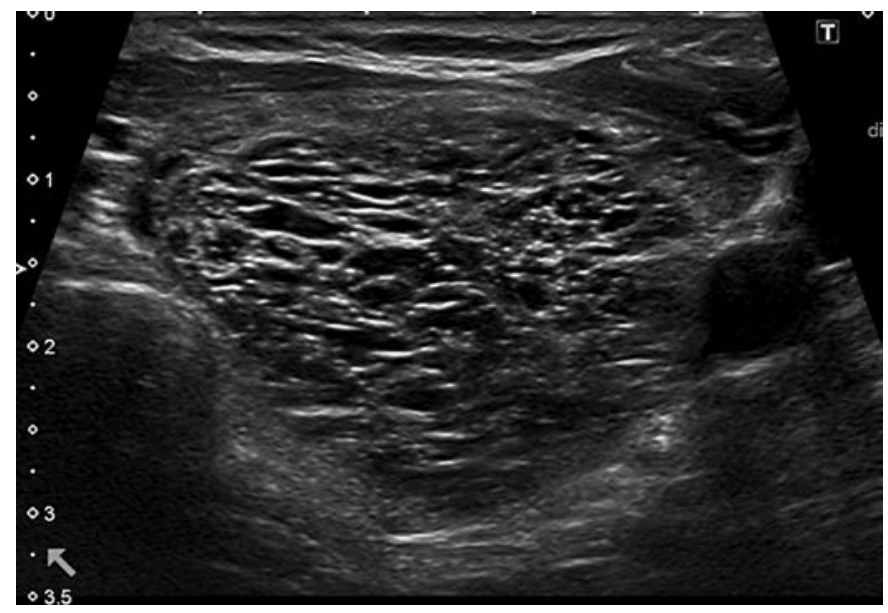

Fig. 3. EU-TIRADS 2: spongiform nodule. Transverse plane.

solid component, the nodule should be included in the low-risk category.

Spongiform Nodules. Composed of tiny cystic spaces involving the entire nodule; disregard their size; separated by numerous isoechoic septa. If the cystic spaces do not involve the entire nodule, the nodule should be considered as low risk.

\section{Recommendation}

R2: Pure cysts and entirely spongiform nodules should be considered as benign. FNA is not indicated (unless for therapeutic purposes, in case of compressive symptoms).

$\mathrm{QOE}=++; \mathrm{SOR}=$ grade 1

\section{Low-Risk Category (EU-TIRADS 3)}

Risk of malignancy: 2-4\% [26].
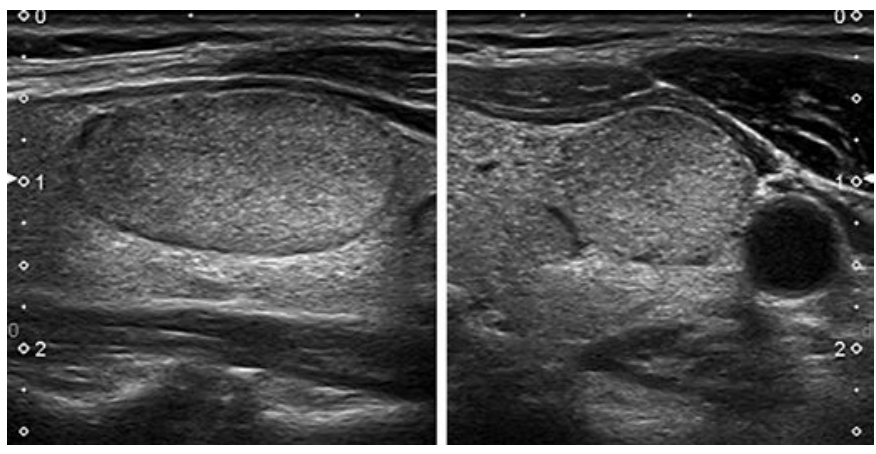

Fig. 4. EU-TIRADS 3: low-risk isoechoic nodule with an oval shape and smooth margins without any high-risk features. Longitudinal (left) and transverse (right) planes.

\section{Definition}

Pattern. Oval shape, smooth margins, isoechoic or hyperechoic, without any feature of high risk (see below) (Fig. 4, 5).

\section{Background and Comments}

Nodules with these characteristics have a low risk of malignancy, and FNA should usually be considered only for nodules $>20 \mathrm{~mm}$. The $20-\mathrm{mm}$ threshold has been chosen based on the argument that distant metastases are rarely observed arising from follicular cancers $<2 \mathrm{~cm}$ [27].

Grouped/coalescing isoechoic nodules (Fig. 6) should be included in this category, and FNA should be considered if 1 or more of the nodules is $>20 \mathrm{~mm}$. It should be pointed out, however, that an entirely solid isoechoic nodule corresponds in $<4 \%$ of cases to a follicular cancer or a follicular variant of PTC [28-31]. In contrast, even minimal cystic changes are in favor of benignity [32].

\section{Recommendation}

R3: Oval-shaped, isoechoic, or hyperechoic nodules with smooth margins and no high-risk features should be considered at low risk of malignancy. FNA should usually be performed only for nodules $>20 \mathrm{~mm}$.

$\mathrm{QOE}=++; \mathrm{SOR}=$ grade 1

Intermediate-Risk Category (EU-TIRADS 4)

Risk of malignancy: 6-17\% [15, 20].

\section{Definition}

Pattern. Oval shape, smooth margins, mildly hypoechoic, without any feature of high risk (see below) (Fig. 7). 

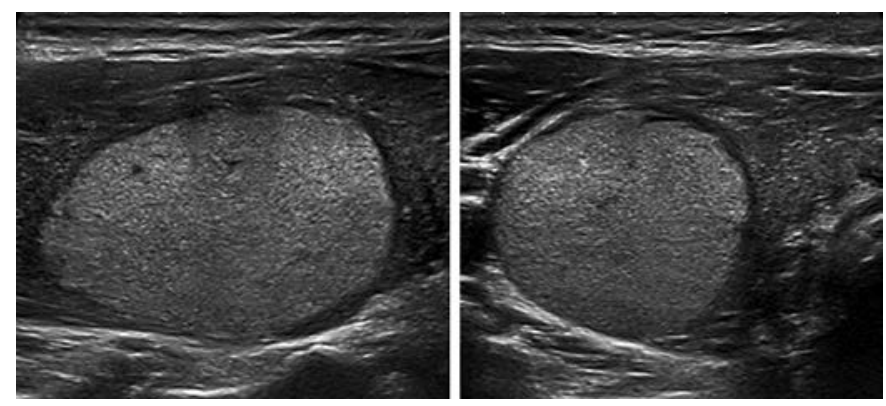

Fig. 5. EU-TIRADS 3: low-risk hyperechoic nodule with an oval shape and smooth margins without any high-risk features. Longitudinal (left) and transverse (right) planes.

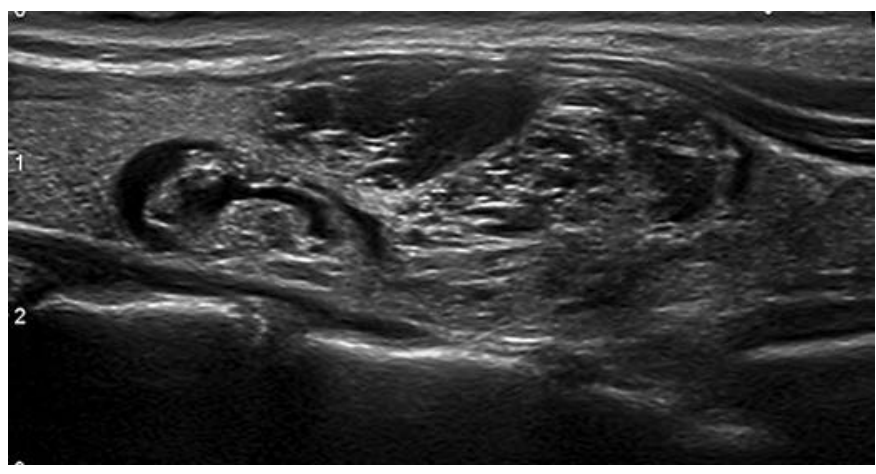

Fig. 6. EU-TIRADS 3: grouped low-risk isoechoic nodules with an oval shape and smooth margins without any high-risk features. Longitudinal plane.
Fig. 7. EU-TIRADS 4: intermediate-risk, mildly hypoechoic nodule with an oval shape and smooth margins without any high-risk features. Longitudinal (left) and transverse (right) planes.
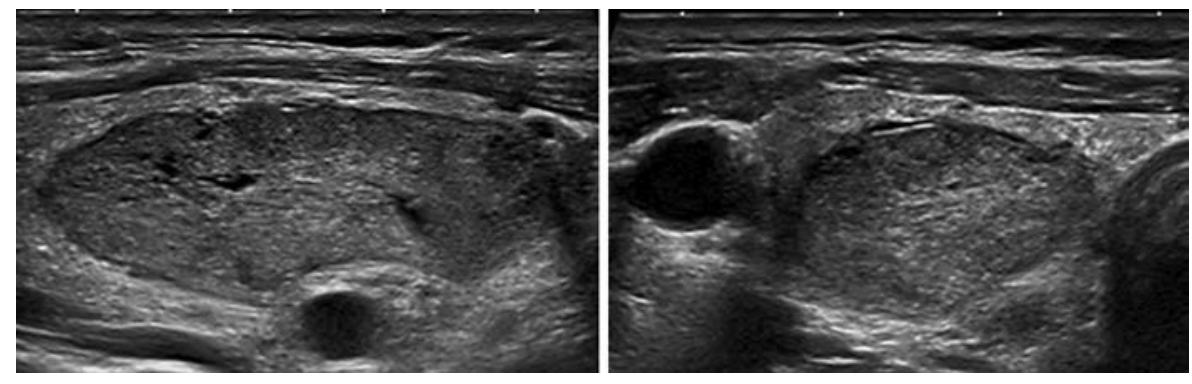

\section{Background and Comments}

The difference between the low-risk and the intermediate-risk category lies in the echogenicity of the solid part of the nodule. In case of heterogeneous echogenicity of the solid component, the presence of any hypoechoic tissue classifies the nodule as intermediate risk.

Other features may modulate the risk of malignancy in this category. The presence of a thin halo, a partially cystic composition, comet-tail artifacts, peripheral vascularity, and low stiffness lower the malignancy risk. In the Korean TIRADS, partially cystic nodules are considered to be low-risk lesions regardless of their echogenicity, and only entirely solid hypoechoic nodules are included in the intermediate-risk category. However, the Korean lowrisk category has a $3-15 \%$ risk of malignancy, which is closer to the intermediate-risk category as defined by the present ETA guidelines. Thus, we consider all hypoechoic nodules as intermediate risk, including those with cystic areas, while acknowledging that the risk is lower in partially cystic than in entirely solid nodules. Features such as discontinuous peripheral/rim macrocalcifications, a thick halo, predominantly central vascularity, and high stiffness could raise the malignancy risk. Given the intermediate risk of EU-TIRADS 4 nodules, the task force chose to define the threshold for FNA in that group as 15 $\mathrm{mm}$, which is in between the thresholds given for EUTIRADS 5 and EU-TIRADS 3 nodules.

\section{Recommendation}

R4: Oval-shaped, mildly hypoechoic nodules with smooth margins and no high-risk features should be considered at intermediate risk of malignancy. FNA should usually be performed for nodules $>15 \mathrm{~mm}$.

$\mathrm{QOE}=++$; $\mathrm{SOR}=$ grade 1

High-Risk Category (EU-TIRADS 5)

Risk of malignancy: $26-87 \%[26,33]$.

\section{Definition}

Pattern. Nodules with at least 1 of the following highrisk features: non-oval shape, irregular margins, microcalcifications, and marked hypoechogenicity (Fig. 8-11).

\section{Background and Comments}

These four US features were originally described in 2002; the average malignancy risk of such nodules was around 56\% [6], but increasing with the number of suspi- 

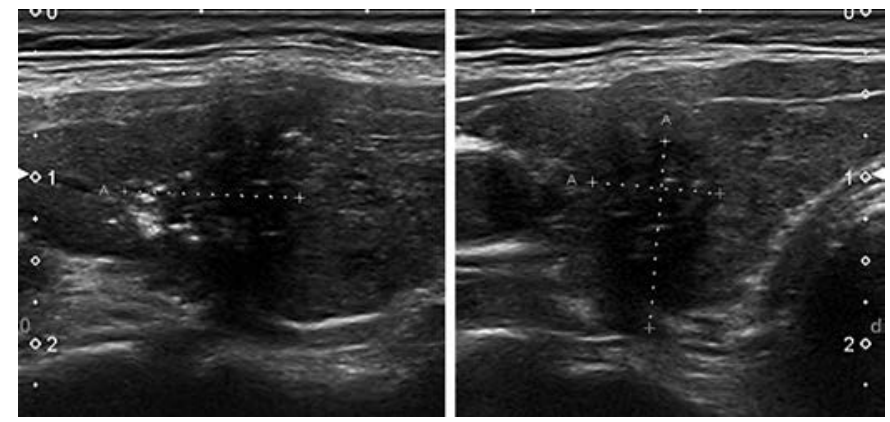

Fig. 8. EU-TIRADS 5: high-risk nodule with a taller-than-wide shape, irregular margins, microcalcifications, and marked hypoechogenicity. Longitudinal (left) and transverse (right) planes. $11 \times 8 \times 11 \mathrm{~mm}$ (length $\times$ width $\times$ thickness).
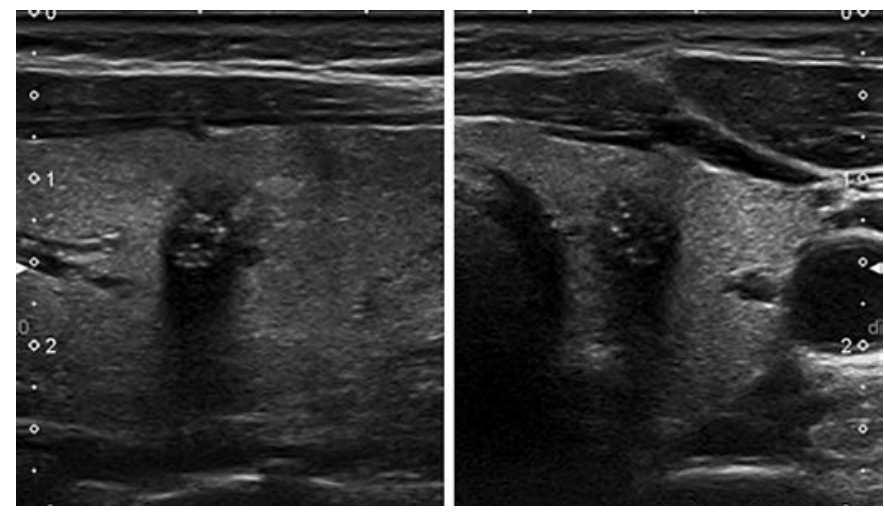

Fig. 9. EU-TIRADS 5: high-risk nodule with a non-oval shape, spiculated margins, microcalcifications, and marked hypoechogenicity. Longitudinal (left) and transverse (right) planes.

cious features $[15,26]$. This partly explains the wide range of malignancy risk in this category. All these characteristics show high rates of specificity $(83-84 \%)$, but also low rates of sensitivity (26-59\%) [6]. Marked hypoechogenicity has the lowest sensitivity of the four features, and is only specific if the nodule is solid and not the scar of a healed cyst [34]. The value of these features is also dependent on composition [16]. In partially cystic nodules, microcalcifications are the best predictor of malignancy, whereas other features seem less significant [16]. The number of spiculations, lobulations, or punctate echogenic foci has to be taken into account to gain specificity, which increases with the number of these anomalies.
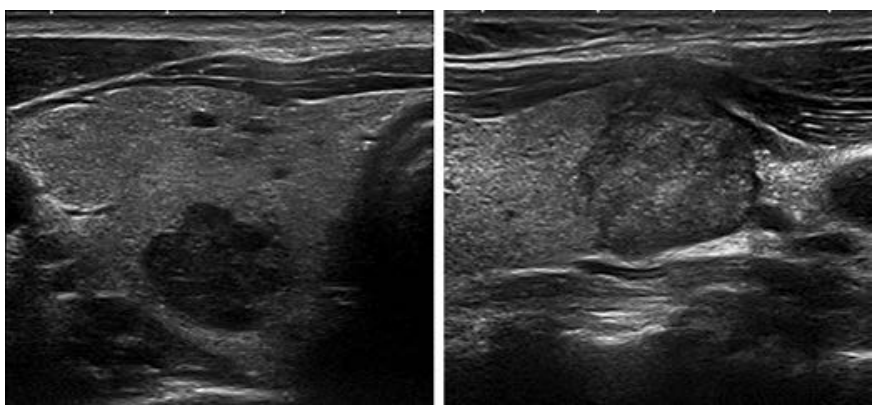

Fig. 10. EU-TIRADS 5: two different examples of high-risk hypoechoic nodules with lobulated margins in the transverse (left picture) and longitudinal (right picture) planes.

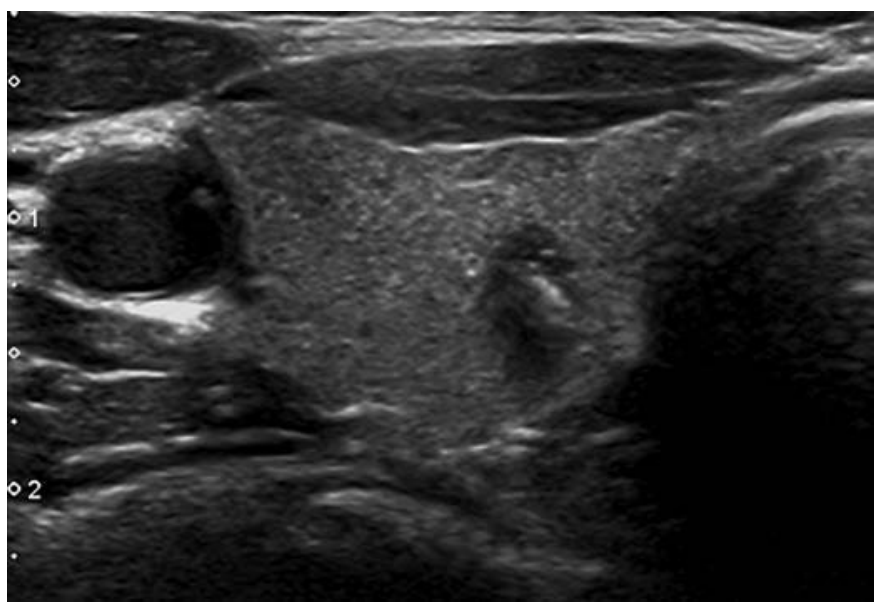

Fig. 11. EU-TIRADS 5: high-risk nodule with a taller-than-wide shape in the transverse plane.

All such nodules $>10 \mathrm{~mm}$ should undergo FNA, unless a patient is inoperable or has a low life expectancy from other comorbidities. In case of a first benign cytological result, FNA should be repeated within 3 months to reduce the rate of false-negative samples.

In case of subcentimeter nodules with high-risk US features, active surveillance is recommended, provided that there are no abnormal lymph nodes and the patient is willing to accept regular US scanning. It is known that few or none of these patients will develop distant metastasis or die of their disease even if the nodule corresponds to a carcinoma [35]. In case of proven growth or detection of a suspicious lymph node during surveillance, FNA should be performed. 


\section{Recommendation}

R5: Nodules having at least 1 suspicious US feature (i.e., a non-oval shape, irregular margins, microcalcifications, or marked hypoechogenicity) should be considered at high risk of malignancy, increasing with the number of suspicious features. FNA should be performed for nodules $>10 \mathrm{~mm}$.

$\mathrm{QOE}=++; \mathrm{SOR}=$ grade 1

Patients with subcentimeter nodules with highly suspicious US features and no abnormal lymph nodes can have the choice of active surveillance or FNA.

\section{US Management in Multinodular Disease}

EU-TIRADS scoring is useful in multinodular thyroid disease to select nodules for FNA. The following process can be applied:

1. Begin looking for high-risk nodules and describe them, disregarding their size; perform FNA if the nodule is $>10 \mathrm{~mm}$

2. Look for intermediate-risk nodules; describe those $>5 \mathrm{~mm}$ and perform FNA if they are $>15 \mathrm{~mm}$

3. Look for low-risk nodules; describe those $>10 \mathrm{~mm}$ and perform FNA if they are $>20 \mathrm{~mm}$

4. If there are numerous nodules, at least the 3 most important ones (according to the risk and size criteria) should be described in detail using the above process

\section{Importance of Other US Findings}

Shape, margins, echogenicity, composition, and hyperechoic foci are the fundamental US features that allow obtaining a TIRADS score. However, several accessory US features can be used to refine the risk stratification assessment and modulate the indications for FNA.

\section{Suspicious Lymphadenopathy}

A US survey of the cervical lymph nodes should be performed on all patients with thyroid nodules, especially those with intermediate- and high-risk ones. The lymph nodes can be assessed as suggested in the ETA guidelines. An FNA of a lymph node for cytological analysis and thyroglobulin or calcitonin washouts should be performed in case of suspicious US features [36].

\section{Recommendation}

R6: US assessment of the lymph nodes is advised for all thyroid nodules but is mandatory for intermediateand high-risk ones. In case of a suspicious lymph node of thyroid origin, FNA of the lymph node and FNA of the most suspicious thyroid nodule(s) should be performed.

$\mathrm{QOE}=+++$; $\mathrm{SOR}=$ grade 1

Guidelines for US Malignancy Risk

Stratification of Thyroid Nodules in Adults
Extrathyroidal Extension [37-40]

Protrusion into the adjacent structures and disruption of the capsular margin (online suppl. Fig. 1) can be considered as specific features for the diagnosis of extrathyroidal invasion. The risk of extrathyroidal invasion reaches $61 \%$ in that case, of which $31 \%$ is the risk of macroscopic invasion. They indicate invasive malignancy. Capsular abutment (online suppl. Fig. 2) has less specificity. On the other hand, the presence of a $>2-\mathrm{mm}$ normal thyroid parenchyma between the nodule and a continuous capsule (online suppl. Fig. 3) reduces the risk of microscopic extrathyroidal extension to $<6 \%$ with little or no chance of macroscopic invasion.

\section{Recommendation}

R7: Capsular bulging, disruption, or abutment by the thyroid nodule are indicative of extrathyroidal extension and should be described in the report.

$\mathrm{QOE}=++$; $\mathrm{SOR}=$ grade 1

Macrocalcifications and Hyperechoic Spots [41-45]

A careful definition of these terms is mandatory.

Macrocalcifications

Macrocalcifications can be defined as echogenic foci $>1 \mathrm{~mm}$ in size with posterior shadowing. Three different patterns can be described:

1. Central intranodular macrocalcifications alone: not consistently associated with malignancy (online suppl. Fig. 4)

2. Isolated macrocalcification, occupying an entirely calcified nodule: low risk (online suppl. Fig. 5)

3. Rim (peripheral or curvilinear) or eggshell calcifications at the nodule margin: may increase the malignancy risk if disrupted (online suppl. Fig. 6)

Hyperechoic Spots

Hyperechoic spots correspond to peri-millimeter hyperechoic foci and may be caused by the following:

1. Colloid crystals or fibrin debris, which generate comet-tail artifacts/reverberations and are almost always suggestive of benignity (online suppl. Fig. 7)

2. Posterior acoustic enhancement of the back wall of a microcystic area; this is mostly seen with high-frequency probes and may be better analyzed by magnifying the image and reducing the compounding; they are suggestive of benignity (online suppl. Fig. 8)

3. True microcalcifications correspond to psammoma bodies and are multiple round echogenic foci around $1 \mathrm{~mm}$ in size without posterior shadowing located in the solid component of a nodule (online suppl. Fig. 9); 
microcalcifications are highly suggestive of malignancy, in particular when associated with macrocalcifications

4. Hyperechoic spots of uncertain significance that cannot be attributed with certainty to one of the three above categories; rather linear than round, and with no microcystic cavities or comet-tail artifacts (online suppl. Fig. 10)

\section{Recommendation}

R8: Macrocalcifications alone are not specific for malignancy. Their presence should be correlated with other US features supporting FNA. True microcalcifications should be differentiated from other echogenic spots, and such nodules must undergo FNA. Echogenic spots with comet-tail artifacts are suggestive of benignity.

$\mathrm{QOE}=++; \mathrm{SOR}=$ grade 2

\section{Halo}

A halo (online suppl. Fig. 11) is thought to correspond either to the capsule of the nodule or to the surrounding capsular vessels, or even sometimes to the adjacent compressed parenchyma. A thin halo reduces the risk of malignancy (DOR of 0.3), while a thick halo or absence of a halo increases it (DOR of 3.4) [33]. Campanella et al. [10] reported a high risk of malignancy associated with an absent halo (7.1; 95\% CI: 3.7-13.7). Remonti et al. [9] found a sensitivity of $57 \%$, a specificity of $72 \%$, and a positive likelihood ratio of 2 for an absent halo. Zhang et al. [46] reported that an absent or thick halo (online suppl. Fig. 12) increased the risk of follicular cancer. However, no clear-cut definition of thin and thick can be provided.

\section{Vascularity: Doppler US}

Definition

The blood flow of thyroid nodules can be studied with various US imaging modalities, including color Doppler, power Doppler, high-resolution studies of microvascularity, and pulsed wave Doppler, giving either color images or plot velocities over time.

For color-derived techniques, the blood flow can be classified into types I-III (online suppl. Fig. 13-15) according to the definitions given in the Appendix ("Vascularity").

\section{Background and Comment}

Real-time Doppler US is widely used in clinical practice and in US reports. Malignant nodules are more prone to have type III vascularity, while benign nodules tend to show type I and II signal patterns. However, the intranodular signal increases also with an increasing size of be- nign nodules. As for type III vascularity, the sensitivity, specificity, and positive predictive value for malignancy are low, but they may be increased by additional suspicious sonographic features. The Doppler criteria remain controversial [47], mainly because the sensitivity of Doppler is highly dependent on the US equipment and settings, and because the definition of central vascularity has a low interobserver agreement. Moreover, quantitative analysis of the color signals, although studied, is not well established and is time-consuming [48]. Therefore, the ETA task force does not recommend the inclusion of Doppler assessment in the TIRADS score. However, it can be used to differentiate solid tissue from thick colloid, or to enhance the detection of the limits of a nodule in an isoechoic parenchyma.

\section{Recommendation}

R9: The routine use of Doppler US is not recommended for US malignancy risk stratification.

$\mathrm{QOE}=+; \mathrm{SOR}=$ grade 2

\section{Stiffness: Elastography}

\section{Definition}

By US elastography, the stiffness of a nodule is analyzed, either by measuring the amount of distortion that occurs when the nodule responds to an external pressure (strain elastography) or by measuring the speed of the shear wave produced by a US pulse (shear wave elastography [SWE], acoustic radiation force impulse).

Strain elastography uses 3- to 5-point elasticity scales obtained from qualitative observations of colored pictures. Different systems of scoring have been described to classify stiffness [49, 50]. Semiquantitative measurements, i.e., the strain index, can be obtained by comparing normal thyroid tissue and nodule strains, and they may be slightly more informative [51] (online suppl. Fig. 16, 17). The results of SWE can be expressed as color maps, ratios, or absolute values in $\mathrm{kPa}$ or $\mathrm{m} / \mathrm{s}$ (online suppl. Fig. 18, 19). Different cutoff values have also been reported, but these are disputable and susceptible to affecting sensitivity and specificity $[52,53]$.

\section{Background and Comments}

Both strain elastography and SWE have many limitations and cannot reliably be applied to:

- large nodules (>30 mm);

- nodules with macrocalcifications;

- cystic nodules;

- deeply located and/or isthmic nodules; and

- coalescent nodules. 
Table 2. EU-TIRADS categories and risk of malignancy

\begin{tabular}{|c|c|c|}
\hline Category & US features & $\begin{array}{l}\text { Malignancy } \\
\text { risk, \% }\end{array}$ \\
\hline EU-TIRADS 1: normal & No nodules & None \\
\hline EU-TIRADS 2: benign & $\begin{array}{l}\text { Pure cyst } \\
\text { Entirely spongiform }\end{array}$ & $\cong 0$ \\
\hline EU-TIRADS 3: low risk & $\begin{array}{l}\text { Ovoid, smooth isoechoic/hyperechoic } \\
\text { No features of high suspicion }\end{array}$ & $2-4$ \\
\hline EU-TIRADS 4: intermediate risk & $\begin{array}{l}\text { Ovoid, smooth, mildly hypoechoic } \\
\text { No features of high suspicion }\end{array}$ & $6-17$ \\
\hline EU-TIRADS 5: high risk & $\begin{array}{l}\text { At least } 1 \text { of the following features of high suspicion: } \\
\text { - Irregular shape } \\
\text { - Irregular margins } \\
\text { - Microcalcifications } \\
\text { - Marked hypoechogenicity (and solid) }\end{array}$ & $26-87$ \\
\hline
\end{tabular}

EU-TIRADS, European Thyroid Imaging Reporting and Data System; US, ultrasound.

Moreover, the interobserver variability is high due to differences in compression level, type of software used, imaging plane, data acquisition, and scoring method [54].

Two meta-analyses, based on studies performed under ideal conditions, showed that strain elastography has a high sensitivity and negative predictive value (NPV) but a low positive predictive value for the detection of PTC [55-57]. In a meta-analysis of SWE by Zhang et al. [58], a $3 \%$ false negative rate was observed, demonstrating that SWE to a large extent is capable of excluding malignancy and also is likely to have a high NPV. Unfortunately, no clear threshold could be obtained, as values ranged from 35 to $90 \mathrm{kPa}$ across studies.

Until well-controlled, large, multicenter studies will have been carried out in order to define a reliable and reproducible threshold for delineating benign from malignant nodules, and since it is questionable if elastography adds any substantial value to grayscale US [59-61], the task force cannot recommend the systematic use of elastography, nor its direct integration into the risk stratification system.

\section{Recommendation}

R10: Elastography should not replace grayscale study, but it may be used as a complementary tool for assessing nodules for FNA, especially due to its high NPV.

$\mathrm{QOE}=++, \mathrm{SOR}=$ grade 2

\section{Nodule Growth}

Whether thyroid cancer - not diagnosed at the initial evaluation - can be predicted by nodular growth assessed by serial US has been explored in a meta-analysis involving 2,743 patients in 7 studies [62]. The results suggest that nodule growth cannot accurately discriminate between benign and malignant lesions. In histologically proven thyroid cancer, the likelihood ratios of nodule growth and of no growth were 0.83 (95\% CI: 0.56-1.2) and 1.2 (95\% CI: $0.82-1.8$ ), respectively, corresponding to a DOR of 0.58 (95\% CI: $0.26-1.3$ ). When the diagnosis was based on repeated FNA, the likelihood ratios were 1.8 (95\% CI: 0.48-6.4) for nodule growth and 0.53 (95\% CI: $0.30-0.96)$ for no growth, the DOR being 2.2 (95\% CI: $0.26-18)$. The results were inconsistent across the studies and with wide confidence intervals, and thus warrant low confidence.

\section{Recommendation}

R11: Routine determination of nodule growth by serial thyroid US assessments, in order to predict cancer, is not justified.

$$
\mathrm{QOE}=++; \mathrm{SOR}=\text { grade } 2
$$

\section{The EU-TIRADS: A Novel Tool for Risk Stratification of Thyroid Nodules}

US imaging is the key examination in the initial evaluation and follow-up of thyroid nodules and cancer. In order to enhance the interobserver reproducibility of de- 
Fig. 12. Algorithm of EU-TIRADS for malignancy risk stratification and fine-needle aspiration (FNA) decision-making. ${ }^{*}$ FNA should be performed in case suspicious lymph nodes are found.

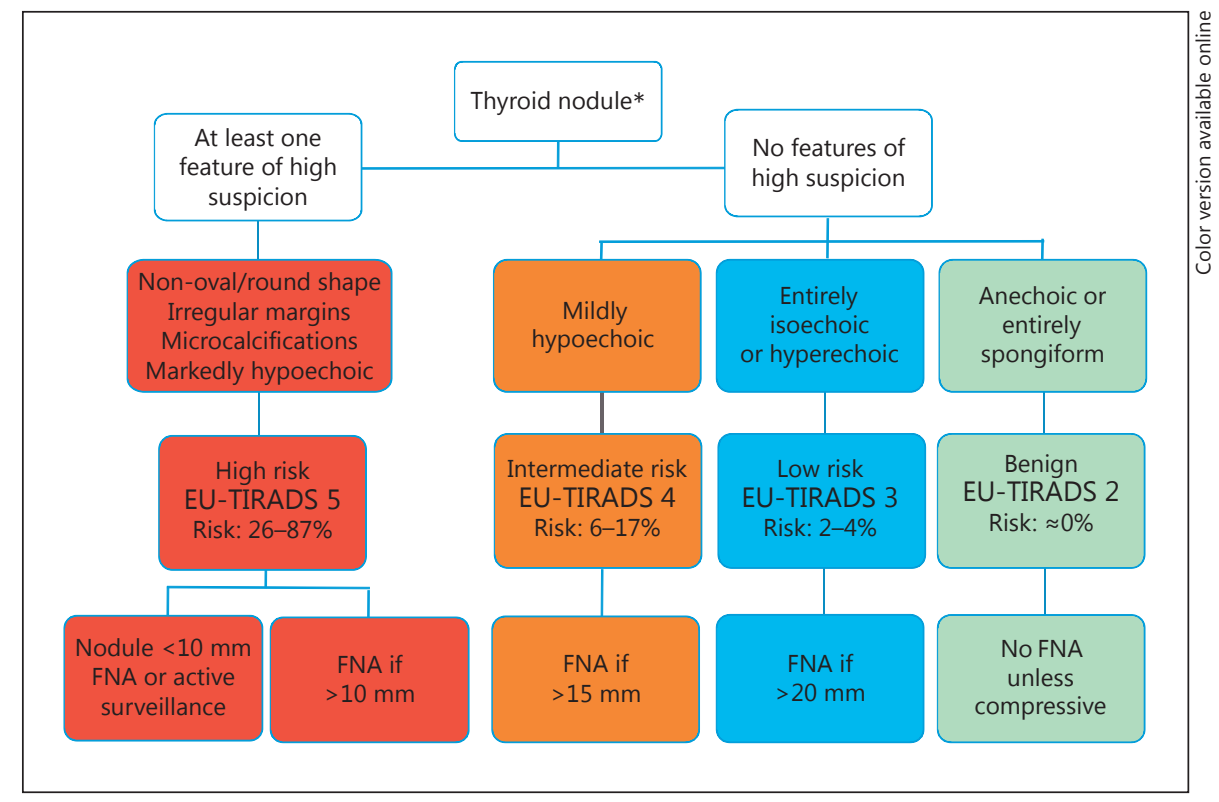

scriptions and to simplify communication of the results, the ETA task force has issued a new simplified TIRADS, to be called EU-TIRADS. In accordance with the aims of this work as outlined above, the system has the following: - A structured and standardized report (Table 1)

- A lexicon to describe nodules adequately (Appendix)

- Five assessment categories, corresponding to a scoring system based on the US features: one category including the absence of thyroid nodules, and the other four including benign and low-, intermediate-, and highrisk groups, respectively. The nodule is attributed a number from 1 to 5, according to the EU-TIRADS categories, which reflects an increasing risk of malignancy (Table 2)

- A practical image guide illustrating each assessment category, as well as specific features and patterns (Fig. 2-12; online suppl. Fig. 1-19)

- A clinical algorithm for selection criteria for FNA

- A flow diagram which summarizes the US features, scoring system, and recommendations for FNA (Fig. 12)

The EU-TIRADS scoring system is based on searching for echogenic features of high suspicion. Many elements from the French system have been included; this system has been prospectively validated, and its diagnostic value confirmed by Yoon et al. [63] in a study of 4,696 nodules, which showed its high sensitivity and NPV. Although the EU-TIRADS remains to be applied and tested in large prospective studies, the task force assumes that the diagnostic validity is high, and close to that of the French system. Compared to other risk stratification systems, the main purpose of the EU-TIRADS is easy guidance in using specific US features to detect thyroid carcinomas with a high sensitivity while keeping a high NPV. This, in turn, should allow reducing unnecessary FNA procedures.

\section{Disclosure Statement}

The task force members have nothing to disclose.

\section{Appendix on US Terminology of Thyroid Nodules $[21,23]$}

Composition: proportion of soft tissue or fluid in a nodule

- Solid: composed almost entirely of soft tissue with $<10 \%$ of liquid

- Mixed predominantly solid: liquid component $>10$ but $<50 \%$ of the nodule volume

- Mixed predominantly cystic: liquid component $>50$ but $<90 \%$ of the nodule volume

- Cystic: composed entirely or nearly entirely of liquid

- Spongiform appearance: tiny cystic spaces separated by thin septa

Comet tail: echogenic foci showing comet-like echogenic tails generated by reverberation artifacts within the cystic component Egg shell calcification: echogenic line surrounding the nodule giving the appearance of a discrete calcified wall, along with marked posterior acoustic shadowing 
Echogenicity: (in case the echogenicity of the surrounding thyroid tissue is decreased, such as in Hashimoto thyroiditis, the echogenicity of the solid component can be described relative to the normal submandibular salivary glands)

- Mildly hypoechoic: refers to an appearance darker than the normal surrounding thyroid parenchyma, but less dark than the surrounding strap muscles

- Isoechoic: similar brightness to the surrounding thyroid parenchyma

- Markedly hypoechoic: refers to an appearance of the nodule darker than the surrounding strap muscles

- Hyperechoic: brighter appearance than the surrounding thyroid parenchyma

Echotexture: characterizes the uniform or multiform appearance of the solid portion of a nodule

- Heterogeneous: mixed isoechoic and hypoechoic echogenicity of the solid portion of a nodule

- Homogeneous: uniform appearance of the solid portion of a nodule

Halo/rim: sonolucent black outline that surrounds a nodule; can be described as thin or thick

Macrocalcification: $>1-\mathrm{mm}$ coarse and large calcification with posterior acoustic shadowing

Microcalcification: $<1-\mathrm{mm}$, most often round calcification

Margin: describes the outline of the thyroid nodule

- Smooth margin: clear demarcation to the surrounding thyroid parenchyma
- Ill-defined margin: lack of a clear demarcation to the surrounding thyroid parenchyma; ill-defined margins are distinct from irregular ones and do not alter the nodule's risk category

- Irregular margin:

- Spiculated: presence of 1 or more sharp angles or spiculations on the margin

- Microlobulated: presence of 1 or more smooth, focal, round protrusions on the margin

Nodule: nodulus (Latin) - small knot; lump

Shape:

- Oval shape: the anteroposterior diameter of a nodule is less than its transverse diameter on the transverse and longitudinal planes

- Round: the anteroposterior diameter of a nodule is equal to its transverse diameter on the transverse and longitudinal planes

- Taller than wide: the ratio of the anteroposterior-to-transverse diameter of a nodule is $>1$

- Taller than long: the ratio of the anteroposterior-to-longitudinal diameter is $>1$

Vascularity:

- Type I: absence of intranodular or perinodular flow

- Type II: presence of perinodular and/or slight intranodular flow

- Type III: presence of marked intranodular and slight perinodular flow

\section{References}

1 Russ G, Leboulleux S, Leenhardt L, Hegedüs L: Thyroid incidentalomas: epidemiology, risk stratification with ultrasound and workup. Eur Thyroid J 2014;3:154-163.

-2 Ross DS: Nonpalpable thyroid nodules managing an epidemic. J Clin Endocrinol Metab 2002;87:1938-1940.

>3 Burman KD, Wartofsky L: Thyroid nodules. N Engl J Med 2015;373:2347-2356.

4 Papini E, Guglielmi R, Bianchini A, Crescenzi A, Taccogna S, Nardi F, Panunzi C, Rinaldi R, Toscano V, Pacella CM: Risk of malignancy in nonpalpable thyroid nodules: predictive value of ultrasound and color-Doppler features. J Clin Endocrinol Metab 2002;7:1941-1946.

5 Bonavita JA, Mayo J, Babb J, Bennett G, Oweity T, Macari M, Yee J: Pattern recognition of benign nodules at ultrasound of the thyroid: which nodules can be left alone? AJR Am J Roentgenol 2009;193:207-213.

-6 Kim EK, Park CS, Chung WY, Oh KK, Kim DI, Lee JT, Yoo HS: New sonographic criteria for recommending fine-needle aspiration biopsy of nonpalpable solid nodules of the thyroid. AJR Am J Roentgenol 2002;178:687-691.

7 Rago T, Vitti P, Chiovato L, Mazzeo S, De Liperi A, Miccoli P, Viacava P, Bogazzi F, Martino E, Pinchera A: Role of conventional ultrasonography and color flow-Doppler sonography in predicting malignancy in "cold" thyroid nodules. Eur J Endocrinol 1998; 138:41-46.
-8 Brito JP, Gionfriddo MR, Al Nofal A, Boehmer KR, Leppin AL, Reading C, Callstrom M, Elraiyah TA, Prokop LJ, Stan MN, Murad MH, Morris JC, Montori VM: The accuracy of thyroid nodule ultrasound to predict thyroid cancer: systematic review and meta-analysis. J Clin Endocrinol Metab 2014;99:1253-1263.

$\checkmark 9$ Remonti LR, Kramer CK, Leitão CB, Pinto LC, Gross JL: Thyroid ultrasound features and risk of carcinoma: a systematic review and meta-analysis of observational studies. Thyroid 2015;25:538-550.

10 Campanella P, Ianni F, Rota CA, Corsello SM, Pontecorvi A: Quantification of cancer risk of each clinical and ultrasonographic suspicious feature of thyroid nodules: a systematic review and meta-analysis. Eur J Endocrinol 2014;170:R203-R211.

$\checkmark 11$ Choi SH, Kim EK, Kwak JY, Kim MJ, Son EJ: Interobserver and intraobserver variations in ultrasound assessment of thyroid nodules. Thyroid 2010;20:167-172.

12 Reading CC, Charboneau JW, Hay JD, Sebo TJ: Sonography of thyroid nodules: a "classic pattern" diagnostic approach. Ultrasound Q 2005;21:157-165.

13 Russ G: Risk stratification of thyroid nodules on ultrasonography with the French TIRADS: description and reflections. Ultrasonography 2016;35:25-38.
14 Horvath E, Majlis S, Rossi R, Franco C, Niedmann JP, Castro A, Dominguez M: An ultrasonogram reporting system for thyroid nodules stratifying cancer risk for clinical management. J Clin Endocrinol Metab 2009; 94:1748-1751.

15 Russ G, Royer B, Bigorgne C, Rouxel A, Bienvenu-Perrard $M$, Leenhardt L: Prospective evaluation of thyroid imaging reporting and data system on 4,550 nodules with and without elastography. Eur J Endocrinol 2013; 168:649-655

16 Na DG, Baek JH, Sung JY, Kim JH, Kim JK, Choi YJ, Seo H: Thyroid imaging reporting and data system risk stratification of thyroid nodules: categorization based on solidity and echogenicity. Thyroid 2016;26:562572 .

17 Haugen BR, Alexander EK, Bible KC, Doherty GM, Mandel SJ, Nikiforov YE, Pacini F, Randolph GW, Sawka AM, Schlumberger M, Schuff KG, Sherman SI, Sosa JA, Steward DL, Tuttle RM, Wartofsky L: 2015 American Thyroid Association management guidelines for adult patients with thyroid nodules and differentiated thyroid cancer: the American Thyroid Association Guidelines Task Force on Thyroid Nodules and Differentiated Thyroid Cancer. Thyroid 2016;26:1-133.
Guidelines for US Malignancy Risk

Stratification of Thyroid Nodules in Adults 
18 Gharib H, Papini E, Garber JR, Duick DS, Harrell RM, Hegedüs L, Paschke R, Valcavi R, Vitti P; AACE/ACE/AME Task Force on Thyroid Nodules: American Association of Clinical Endocrinologists, American College of Endocrinology, and Associazione Medici Endocrinologi medical guidelines for clinical practice for the diagnosis and management of thyroid nodules - 2016 update. Endocr Pract 2016;22:622-639.

19 Wei X, Li Y, Zhang S, Gao M: Meta-analysis of thyroid imaging reporting and data system in the ultrasonographic diagnosis of 10,437 thyroid nodules. Head Neck 2016;38:309315.

-20 Yoon JH, Lee HS, Kim EK, Moon HJ, Kwak JY: Malignancy risk stratification of thyroid nodules: comparison between the Thyroid Imaging Reporting and Data System and the 2014 American Thyroid Association management guidelines. Radiology 2016;278:917924.

-21 Su HK, Dos Reis LL, Lupo MA, Milas M, Orloff LA, Langer JE, Brett EM, Kazam E, Lee SL, Minkowitz G, Alpert EH, Dewey EH, Urken ML: Striving toward standardization of reporting of ultrasound features of thyroid nodules and lymph nodes: a multidisciplinary consensus statement. Thyroid 2014;24:13411349.

-22 Andrioli M, Carzaniga C, Persani L: Standardized ultrasound report for thyroid nodules: the endocrinologist's viewpoint. Eur Thyroid J 2013;2:37-48.

23 Grant EG, Tessler FN, Hoang JK, Langer JE, Beland MD, Berland LL, Cronan JJ, Desser TS, Frates MC, Hamper UM, Middleton WD, Reading CC, Scoutt LM, Stavros AT, Teefey SA: Thyroid ultrasound reporting lexicon: white paper of the ACR Thyroid Imaging, Reporting and Data System (TIRADS) Committee. J Am Coll Radiol 2015;12(pt A):12721279.

24 Tramalloni J, Monpeyssen H, Correas JM, Hélénon O: Thyroid nodule management: ultrasonography, fine-needle cytology (in French). J Radiol 2009;90(pt 2):362-370.

$\checkmark 25$ Virmani V, Hammond I: Sonographic patterns of benign thyroid nodules: verification at our institution. AJR Am J Roentgenol 2011; 196:891-895.

-26 Kwak JY, Han KH, Yoon JH, Moon HJ, Son EJ, Park SH, Jung HK, Choi JS, Kim BM, Kim EK: Thyroid Imaging Reporting and Data System for US features of nodules: a step in establishing better stratification of cancer risk. Radiology 2011;260:892-899.

27 Machens A, Holzhausen HJ, Dralle H: The prognostic value of primary tumor size in papillary and follicular thyroid carcinoma. Cancer 2005;103:2269-2273.

28 Yoon JH, Kim EK, Hong SW, Kwak JY, Kim MJ: Sonographic features of the follicular variant of papillary thyroid carcinoma. J Ultrasound Med 2008;27:1431-1437.
9 Kim DS, Kim JH, Na DG, Park SH, Kim E, Chang KH, Sohn CH, Choi YH: Sonographic features of follicular variant papillary thyroid carcinomas in comparison with conventional papillary thyroid carcinomas. J Ultrasound Med 2009;28:1685-1692.

30 Yoon JH, Kwon HJ, Kim EK, Moon HJ, Kwak JY: The follicular variant of papillary thyroid carcinoma: characteristics of preoperative ultrasonography and cytology. Ultrasonography 2016;35:47-54.

31 Sillery JC, Reading CC, Charboneau JW, Henrichsen TL, Hay ID, Mandrekar JN: Thyroid follicular carcinoma: sonographic features of 50 cases. AJR Am J Roentgenol 2010; 194:44-54.

32 Na DG, Kim JH, Kim DS, Kim SJ: Thyroid nodules with minimal cystic changes have a low risk of malignancy. Ultrasonography 2016;35:153-158.

33 Russ G, Bigorgne C, Royer B, Rouxel A, Bienvenu-Perrard $M$ : The Thyroid Imaging Reporting and Data System (TIRADS) for ultrasound of the thyroid. J Radiol 2011;92:701713.

34 Kim SS, Kim MR, Mok JY, Huh JE, Jeon YK, Kim BH, Kim SJ, Kim YK, Kim IJ: Benign cystic nodules may have ultrasonographic features mimicking papillary thyroid carcinoma during interval changes. Endocr J 2011;58: 633-638.

35 Brito JP, Ito Y, Miyauchi A, Tuttle RM: A clinical framework to facilitate risk stratification when considering an active surveillance alternative to immediate biopsy and surgery in papillary microcarcinoma. Thyroid 2016;26: 144-149.

-36 Leenhardt L, Erdogan MF, Hegedüs L, Mandel SJ, Paschke R, Rago T, Russ G: 2013 European Thyroid Association guidelines for cervical ultrasound scan and ultrasound-guided techniques in the postoperative management of patients with thyroid cancer. Eur Thyroid J 2013;2:147-159.

37 Lee CY, Kim SJ, Ko KR, Chung KW, Lee JH: Predictive factors for extrathyroidal extension of papillary thyroid carcinoma based on preoperative sonography. J Ultrasound Med 2014;33:231-238.

38 Kwak JY, Kim EK, Youk JH, Kim MJ, Son EJ, Choi SH: Extrathyroid extension of well-differentiated papillary thyroid microcarcinoma on US. Thyroid 2008;18:609-614.

39 Moon SJ, Kim DW, Kim SJ, Ha TK, Park HK, Jung SJ: Ultrasound assessment of degrees of extrathyroidal extension in papillary thyroid microcarcinoma. Endocr Pract 2014;20:10371043.

40 Rim JH, Chong S, Ryu HS, Chung BM, Ahn HS: Feasibility study of ultrasonographic criteria for microscopic and macroscopic extrathyroidal extension based on thyroid capsular continuity and tumour contour in patients with papillary thyroid carcinomas. Ultrasound Med and Biol 2016;42:2391-2400.
41 Chammas MC, de Araujo Filho VJ, Moysés RA, Brescia MD, Mulatti GC, Brandão LG, Cerri GG, Ferraz AR: Predictive value for malignancy in the finding of microcalcifications on ultrasonography of thyroid nodules. Head Neck 2008;30:1206-1210.

42 Beland MD, Kwon L, Delellis RA, Cronan JJ, Grant EG: Nonshadowing echogenic foci in thyroid nodules: are certain appearances enough to avoid thyroid biopsy? J Ultrasound Med 2011;30:753-760.

43 Malhi H, Beland MD, Cen SY, Allgood E, Daley K, Martin SE, Cronan JJ, Grant EG: Echogenic foci in thyroid nodules: significance of posterior acoustic artifacts. AJR Am J Roentgenol 2014;203:1310-1316.

44 Na DG, Kim DS, Kim SJ, Ryoo JW, Jung SL: Thyroid nodules with isolated macrocalcification: malignancy risk and diagnostic efficacy of fine-needle aspiration and core needle biopsy. Ultrasonography 2016;35:216-219.

45 Kim BM, Kim MJ, Kim EK, Kwak JY, Hong SW, Son EJ, Kim KH: Sonographic differentiation of thyroid nodules with eggshell calcifications. J Ultrasound Med 2008;27:14251430.

46 Zhang JZ, Hu B: Sonographic features of thyroid follicular carcinoma in comparison with thyroid follicular adenoma. J Ultrasound Med 2014;33:221-227.

- 47 Moon HJ, Kwak JY, Kim MJ, Son EJ, Kim EK: Can vascularity at power Doppler US help predict thyroid malignancy? Radiology 2010; 255:260-269.

48 Lyshchik A, Moses R, Barnes SL, Higashi T, Asato R, Miga MI, Gore JC, Fleischer AC: Quantitative analysis of tumor vascularity in benign and malignant solid thyroid nodules. J Ultrasound Med 2007;26:837-846.

49 Rago T, Santini F, Scutari M, Pinchera A, Vitti P: Elastography: new developments in ultrasound for predicting malignancy in thyroid nodules. J Clin Endocrinol Metab 2007;92: 2917-2922.

50 Asteria C, Giovanardi A, Pizzocaro A, Cozzaglio L, Morabito A, Somalvico F, Zoppo A: US-elastography in the differential diagnosis of benign and malignant thyroid nodules. Thyroid 2008;18:523-531.

51 Sun J, Cai J, Wang X: Real-time ultrasound elastography for differentiation of benign and malignant thyroid nodules: a meta-analysis. J Ultrasound Med 2014;33:495-502.

52 Sebag F, Vaillant-Lombard J, Berbis J, Griset V, Henry JF, Petit P, Oliver C: Shear wave elastography: a new ultrasound imaging mode for the differential diagnosis of benign and malignant thyroid nodules. J Clin Endocrinol Metab 2010;95:5281-5258.

53 Bhatia KS, Tong CS, Cho CC, Yuen EH, Lee YY, Ahuja AT: Shear wave elastography of thyroid nodules in routine clinical practice: preliminary observations and utility for detecting malignancy. Eur Radiol 2012;22:23972406. 
54 Park SH, Kim SJ, Kim EK, Kim MJ, Son EJ, Kwak JY: Interobserver agreement in assessing the sonographic and elastographic features of malignant thyroid nodules. AJR Am J Roentgenol 2009;193:W416-W423.

55 Bojunga J, Herrmann E, Meyer G, Weber S, Zeuzem S, Friedrich-Rust M: Real-time elastography for the differentiation of benign and malignant thyroid nodules: a meta-analysis. Thyroid 2010;20:1145-1150.

-56 Razavi SA, Hadduck TA, Sadigh G, Dwamena BA: Comparative effectiveness of elastographic and B-mode ultrasound criteria for diagnostic discrimination of thyroid nodules: a meta-analysis. AJR Am J Roentgenol 2013; 200:1317-1326.
57 Nell S, Kist JW, Debray TP, de Keizer B, van Oostenbrugge TJ, Borel Rinkes IH, Valk GD, Vriens MR: Qualitative elastography can replace thyroid nodule fine-needle aspiration in patients with soft thyroid nodules. A systematic review and meta-analysis. Eur J Radiol 2015;84:652-661.

58 Zhang B, Ma X, Wu N, Liu L, Liu X, Zhang J, Yang J, Niu T: Shear wave elastography for differentiation of benign and malignant thyroid nodules: a meta-analysis. J Ultrasound Med 2013;32:2163-2169.

59 Moon HJ, Sung JM, Kim EK, Yoon JH, Youk JH, Kwak JY: Diagnostic performance of gray-scale US and elastography in solid thyroid nodules. Radiology 2012;262:1002-1013.

60 Trimboli P, Guglielmi R, Monti S, Misischi I, Graziano F, Nasrollah N, Amendola S, Morgante SN, Deiana MG, Valabrega S, Toscano V, Papini E: Ultrasound sensitivity for thyroid malignancy is increased by real-time elastography: a prospective multicenter study. J Clin Endocrinol Metab 2012;97:4524-4530.
61 Unlütürk U, Erdoğan MF, Demir O, Güllü S, Başkal N: Ultrasound elastography is not superior to grayscale ultrasound in predicting malignancy in thyroid nodules. Thyroid 2012; 22:1031-1038.

62 Singh Ospina N, Maraka S, Espinosa DeYcaza A, O'Keeffe D, Brito JP, Gionfriddo MR, Castro MR, Morris JC, Erwin P, Montori VM: Diagnostic accuracy of thyroid nodule growth to predict malignancy in thyroid nodules with benign cytology: systematic review and metaanalysis. Clin Endocrinol (Oxf) 2016;85:122131.

63 Yoon JH, Han K, Kim EK, Moon HJ, Kwak JY: Diagnosis and management of small thyroid nodules: a comparative study with six guidelines for thyroid nodules. Radiology 2017; 283:560-569. 